\title{
REVIEW OF THE TEXT BY ZULAY C. DÍAZ MONTIEL. RAÚL FORNET - BETANCOURT: INTERSUBJECTIVITY, DIALOGUE AND INTERCULTURAL ETHICS. AN INTERPRETATION FROM LATIN AMERICAN PHILOSOPHY. BRAZIL: NOVA PETRÓ-POLIS: NOVA HARMONIA / UNIVERSIDAD DEL ZULIA, 2017. PP. 96.
}

José Javier Capera Figueroa²

In memory of the Master / Philosopher Álvaro B. Márquez- Fernández (1952-2018)

The need to continue promoting issues not seen in a positive way by the closed groups of power, and those that have made the academy traditional, systemic and functional groups to the interests of those above, constitutes a commitment to go against stream of that kind of history and assume an ethical-political commitment based on the struggles, feelings and emotions of the groups below.

Precisely, it is the proposal that configures the senti-thinking / action of the book written by the thinker Dr. Zulay C. Díaz Montiel, which starts from establishing an open dialogue with the work / thought and ideas of the Cuban philosopher Raúl Fornet - Betancourt in the field of intercultural studies, intersubjectivity and interpretation of cultural discourses from Latin American philosophy. The responsibility carried out by Díaz Montiel, constitutes a stirrup that drives other discussions focused on rethinking an episteme consistent with the praxis and human condition of those below.

1 Translated by Robinson Ospino.

2 Politólogo de la Universidad del Tolima. Maestro en sociología política del Instituto de Investigaciones Dr. José María Luis Mora, y doctorado en Ciencias Sociales y Políticas de la Universidad Iberoamericana (México). Analista político y columnista del periódico el Nuevo Día (Colombia) y Rebelión.org (España). Correo: caperafigueroa@gmail.com - http://josecaperafigueroa.blogspot.mx/ 
The exposed narrative, raises an analytical thread that constitutes the dialogic capacity of the subjects between cultures, which implies a point of enunciation which allows to recognize the existence of a polyphonic and intercultural communicative process, since it generates the necessary conditions to institute a hermeneutical logic based on the horizontal exchange of cultures, based on the emancipatory condition of the subject in his own space of existence / resistance for another social reality more in line with good living in community.

The theoretical process carried out by the thinker Zulay Díaz, becomes a large column, because it recognizes the importance that intercultural, decolonizing and subaltern perspective represents in the epistemic space, since it intends to go beyond the normative dimension, linear and vertical of conceiving culture as a device of functional imposition to the interests of hegemonic groups.

On the contrary, the bet of the book lies in establishing a horizontal dialogue from the main precepts that shape the philosophical thinking of Fornet-Betancourt, which bases part of its theories on the need to overcome the Eurocentric notion of knowledge, and give way to a channel of inter-cultural convergence that has the possibility of communicating the conceptual currents between the fundamental / conflictive scenarios of Europe and Latin America. So, Díaz Montiel. It proposes a long-term hermeneutical exercise, based on the analysis of philosophical discourse and the essential role that constitutes the subject's praxis for promoting a solidary, co-labor and social task that allows interaction from and with otherness in the middle of their differences socio-cultural background, that is, an intercultural ethical praxis.

The discursiveness conceived in Diaz's work is forged as an epistemic field of a counter-hegemonic character, which breaks into the traditional, linear and monolithic discussions of analyzing culture, on the contrary, is based on an alternative proposal that goes into The function of an enunciation logo that assumes interculturality as a socio-political process legitimized by the demands, needs and feelings of subaltern groups and popular media in democratized public spaces.

In fact, the need to promote the democratized and horizontal use of popular powers symbolizes an intercultural dialogue that starts from the subject's particular condition, although it is committed to promoting the 
constitution of a meeting, un-meeting and recognition space from the condition of freedom, criticism and ethical praxis of the subjects in a scenario of debate, reflection and divergence against the individualistic, utilitarian and traditional logic oriented to de-legitimize and de-prestige the reasons, affections and feelings of the other, being a -Other permeated values, stories and multilingual narratives and good living in community.

The emergence of recognizing a dialogic subject that can constitute a set of narratives, which responds to its immediate context and inter-cultural processes from and with otherness, constitutes the possibility of assuming an ethical praxis at the coexistence and political level, based on the dimension of the struggles / resistance for other alternate and polyphonic realities in the face of the systemic crisis. In turn, it allows us to propose a proposal that goes against the official, institutional and media discourses that make interculturality an instrument of domination by the elites, leaving aside the real sense of building other possible scenarios that make weight to the civilizational crisis of our time.

For this reason, the interculturality that Diaz assumes horizontally from the epistemic dimension of Fornet - Betancourt's thinking, epitomizes an epistemic field that breaks into modern / colonial discussions, giving meaning to the experiences of the colonized subject and the peoples subjected to the violence, dispossession and misery by hegemonic groups in the territories. What it symbolizes, taking a revolutionary leap towards an intercultural philosophy conception that sees the world as a construction of cultural opportunities, from the dialogic praxis between equals and unequals for founding another reality that gives weight to the structural problems of societies subject to rationality own instruments of the capitalist system.

The work of Z. Díaz, leads us to propose a series of epistemic narratives that contribute to the construction of discourses related to the needs / struggles of the groups below. Since it recognizes a type of utopian philosophy that examines interculturality as those long-lasting processes constructed from the dimensions: social-rational-affective-emotional of the subject within the framework of a utopian thought that is consistent with thinking from the reflection another possible spectrum of the world beyond the abysmal veil of modernity / coloniality. 
What denotes a critical point of enunciation, which considers the subject's experience as an intersubjective dimension that serves to constitute tools, schemes and conceptions of a transformative, resilient and popular praxis at the service of the struggles of subaltern groups, being the reflection for taking a political conscience oriented to the possibility of going against the official, bureaucratic and instructional narratives of the hegemonic / colonial power of modern societies.

The present work, is composed as follows: 1) in the first chapter, a question about the philosophical logos in its intercultural praxis is presented, which means recognizing the hierarchy of intercultural studies in dialogue with other disciplines of the social sciences and the humanities, at the same time their epistemic role to be a relevant topic in the contemporary debates of science in the South - Global.

In the second chapter, called "intercultural intersubjectivity," Diaz proposes an epistemic discussion about the Yo-You and he Nos - others from the dimension of an intercultural hermeneutic in Latin America, which becomes the proposition of the existence of a theoretical, conceptual plurality and methodological that manages to unite from a dialogic, critical and self-critical dimension the condition of cultures immersed in a globalized world.

With respect to the third part of the book entitled "Intercultural Dialogue", it is possible to make the leap towards an epistemic construction from the subaltern condition of the subject, which could be recognized as an input to the narratives that make up the studies of colonial (s) On the one hand, it assumes the importance of thinking the interdiscursive and co-experiential level in the dialogic agreement with the other, focused on the constitution of a praxis of liberation towards and with those below.

On the other hand, it assumes the need to reflect on the subject that emerges in the process of intercultural dialogue, starting from the emergency for questioning modernity / coloniality, in order to propose the need for a pluriverse that is consistent with the struggles / demands of the subaltern actors. Therefore, it outlines the need to overcome the teleological empire and make sense of the socio-cultural condition of otherness.

In the last chapter, it focuses on the conception of an intercultural ethic, which can be articulated with recent phenomena: violence, corruption, misery, dehumanization and the systemic crisis of a civilizing nature among others. 
Therefore, it re-constructs a discussion on the human right to intercultural coexistence of a Nos-others, here outlines the need for a political praxis from the condition of otherness, being possible to identify the dimension that denotes interculturality, from a commitment to a fair, ethical and dignified society based on the sociocultural struggles of those below.

The work of the Venezuelan philosopher Zulay Díaz, becomes a reference in the field of critical intercultural studies, those that are focused on rethinking the relations of domination, exploitation and utilitarianism that exist in our societies. What it implies, going beyond the instrumentalist logic of modernity - capitalist, to make the leap towards a perspective of decolonizing the patriarchal, sexist and colonial relations that remain in our times. In this way, aspects such as autonomy, freedom, human rights and dignity are instituted in the pillars that would shape an alternate perspective on interculturality, which gives weight to the normative / bureaucratic vision of the alignment of discourses by of neoliberalism.

The commitment of our chaotic reality and plunged into a world of complexities and crises, refers us to a sphere where coercive spaces become a channel of political transformation, which can serve as a platform for denunciation, struggle and popular information, being the reflection for overcoming the colonial, dominant and repressive culture that has been the modern / colonialist thinking of capitalism. At the same time, it becomes a space that challenges the notion of intercultural practices, thought from the notion of the "civilized" subject, by the contario, assumes the recognition / legitimacy of otherness from their own human and sociocultural condition, which starts from the difference from otherness in the public / private sphere of society.

Finally, Díaz’s book “Raúl Fornet - Betancourt: Intersubjectivity, Dialogue and Intercultural Ethics. An interpretation from Latin American philosophy ", allows us to recognize the epistemic vitality that implies analytical categories such as: intercultural ethics, the intersubjectivity of subaltern reality and open / horizontal dialogue with otherness, being a topic of great relevance in the social sciences, from the reciprocal discussion with the Cuban philosopher, which implies legitimizing the sense of intercultural transformations from the condition of a Latin American philosophy. 
Part of these arguments and reflections can be described in the work of our thinker of the South - Global, which is indebted to her readers, since we could request or invite her to a second version of her work. When we know that we live in difficult times where systemic rights and lefts continue to ignore the struggles / demands of movements, groups, peoples and organizations: social, indigenous, black, popular and peasant, which demand other possible, necessary and urgent worlds. where we can coexist in a dimension of intercultural ethics from and with subaltern groups in their territories.

\section{BOOK COVER}

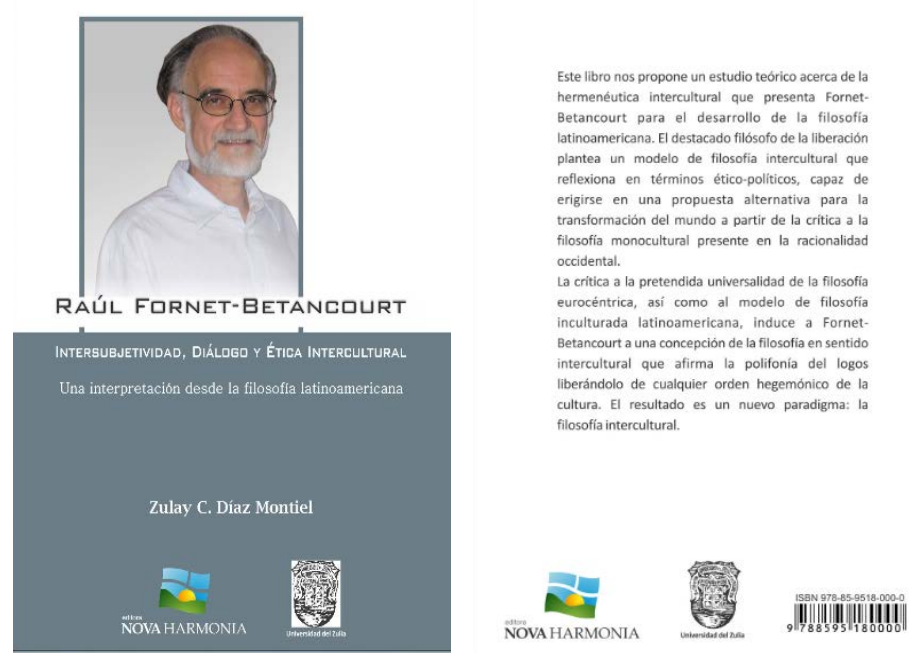

